\title{
The effect of overlearning on response shifting
}

\author{
William F. Caul and H. Wayne Ladvigson \\ CARNEGIE INSTITUTE OF TECHNOLOGY
}

\begin{abstract}
After either criterion learning or overlearning of a first concept 28 college students were shifted to a concept involving a different stimulus attribute (nonreversal shift). The stimuli were sorted into two categories. Overlearning facilitated acquisition of the second concept, $\mathrm{P}=.05$.
\end{abstract}

\section{Problem}

A topic of considerable recent interest concerns the ease with which organisms adjust, when confronted with a discrimination problem, to some change in the problem following different amounts of initial training and overlearning. Part of the interest, no doubt, arises from the lack of consistant findings with infra-human Ss. Any general conclusions about the precise nature of overlearning effects are not possible at present because of divergent results among different species and among different problems within species.

In contrast, the effects of overlearning on response shifting in adult human concept identification appear somewhat clearer. A number of studies using four sorting categories (e. g., Erlebacher \& Archer, 1961; Grant \& Berg, 1948) have shown that nonreversal shifts are facilitated by overlearning. In a direct comparison of the relative effects of overlearning on reversal (RS) and nonreversal shifts (NRS) in adults, Ludvigson and Caul (in press) found that both types of shift appeared to benefit about equally regardless of whether the cards had to be sorted into two or four categories. However, when individual comparisons were made, the effect on a two-category NRS was not significant. In view of inconsistent findings in the general area of response shifting, the present study was undertaken to provide more substantial data regarding this type of shift in concept identification.

\section{Method}

The materials and procedure used were the same as those employed in the previous study (Ludvigson \& Caul, in press). The task required $\mathrm{S}$ to sort 16 response cards into two categories defined by stimulus cards. The top character on the stimulus and response cards was relevant for the Horizontal-Vertical (HV) concept while the relationship between the bottom characters defined the Straight-Oblique (SO) concept. Half of the $28 \mathrm{Ss}$ from introductory psychology classes learned the HV concept before being shifted to the reverse of the SO concept. The remaining Ss were shifted to the reverse of the HV concept after first learning the SO problem. Within each of these groups, seven Ss learned the first concept to a criterion of 10 successive correct responses while the other seven Ss, after meeting this criterion, were given 48 additional trials on the original concept before being shifted. Practice on the second concept continued until the criterion of 10 successive correct responses was reached.

\section{Results and Diseussion}

The mean, median, and range of the numbers of trials to reach criterion (excluding the 10 criterion trials) on the first concept are presented in Table 1. The two concepts appeared to be of approximately equal difficulty and the difference was not significant when analyzed with the Mann-Whitney U test.

Table 2 presents the mean, median, and range of the numbers of trials to learn the second concept for the criterion and overlearning groups. The analysis on these data resulted in a $\mathrm{U}(14,14)$ of 55 which is precisely the value required for significance at the .05 level. Since these data parallel those of the equivalent groups of the previous study and do not differ from them at either the criterion, $\mathrm{U}(10,14)=50.5$, or overlearning level, $\mathrm{U}(10,14)=64.5$, a more powerful test of the overlearning effect can be made by pooling the data across experiments. When this is done, resulting in 24 Ss per group, the overlearning effect is again significant using the Mann-Whitney test, $\mathrm{z}=2.09 ; \mathrm{P}<.05$.

Although overlearning does appear to facilitate a twocategory NRS, it is clear from the large within group variability that there are substantial individual differences in the number of trials needed to learn the second concept. Nevertheless, these data, in conjunction with the previous study, support the conclusion that the effect of overlearning is about the same on RS and NRS for adult humans.

Through what kind of mechanism might overlearning

Table 1

Mean, Median and Range of Numbers of Trials to Learn First Concept

\begin{tabular}{|c|c|c|c|c|c|}
\hline Group & N & Mean & Median & Range & $\underline{U}$ \\
\hline HV & 14 & 12.29 & 3.50 & $0-71$ & U $=85$ \\
\hline so & 14 & 10.79 & 6.75 & $0-49$ & $\underline{\mathrm{D}}>.10$ \\
\hline
\end{tabular}


Table 2

Mean, Median and Range of Numbers of Trials to Learn

Second Concept

\begin{tabular}{|c|c|c|c|c|c|}
\hline \hline Group & N & Mean & Median & Range & U \\
\hline Cr & 14 & 69.5 & 39 & $15-209$ & \multirow{2}{*}{$\begin{array}{l}\mathrm{U}=55 \\
\text { Ov }\end{array}$} \\
\hline
\end{tabular}

produce these results? Some investigators (Furth \& Youniss, 1964; Mackintosh, 1962) have hypothesized that overlearning may, in part, exert its effect on the discriminative shifting of rats and children by facilitating the acquisition and strengthening of a mediating response appropriate to the reinforced attributes of the stimuli. Regardless of whether such a hypothesis holds for rats and children, it does not appear readily applicable to concept shifting in adults since it predicts facilitation for RS but interference for NRS. Most likely adults already possess mediating responses appropriate for the usual concept task, at maximal or near-maximal strength.

It has been suggested that with overlearning, S may more easily recognize a change in reinforcement (Capaldi \& Stevenson, 1957; Furth \& Youniss, 1964). If the ease with which $\mathrm{S}$ recognizes a change is indicated by the rapidity with which $\mathrm{S}$ changes his mode of responding following the shift, then overlearning does facilitate such recognition (Ludvigson \& Caul, in press). The present study further substantiates this conclusion. The median number of trials between the first nonreinforcement in the shift phase and Ss' first overt response which was different from what would have been correct prior to the shift, was 2.5 for criterion Ss and 0.375 for overlearning Ss. This difference is significant, $\mathrm{U}(14,14)=43 ; \mathrm{P}<.02$. However, as may be seen, the facilitation is slight and does not, in itself, appear to account for the large reduction in trials to criterion produced by overlearning. It seems quite likely that other factors are also operating.

\section{References}

CAPALDI, E. J., \& STEVENSON, H. W. Response reversal following different amounts of training. J.comp. physiol. Psychol., 1957, 50, 195-198.

ERLEBACHER, A., \& ARCHER, E. J. Perseveration as a function of degree of learning and percentage of reinforcement in card sorting. J. exp. Psychol., 1961, $62,510-517$.

FURTH, H. G., \& YOUNISS, J. Effect of overtraining on three discrimination shifts in children.J. comp. physiol. Psychol., 1964; 57, 290-293.

GRANT, D. A., \& BERG, E. A. A behavioral analysis of degree of reinforcement and ease of shifting to new responses in a Weigl-type card sorting problem. J. exp. Psychol., 1948, 38, 404-411.

LUDVIGSON, H. W., \& CAUL, W. F. The relative effect of overlearning on reversal and nonreversal shifts with two and four sorting categories. J. exp. Psychol., in press.

MACKINTOSH, N. J. The effects of overtraining on a reversal and nonreversal shift. J. comp. physiol. Psychol., $1962,55,555-559$.

\section{Note}

1. This investigation was supported in part by a grant from the Carnegie Corporation. 